extratropical regions of North America, Europe and South America indicate reduced fire activity during the deglaciation (21 11 cal kyr BP). The tropical latitudes of South America and Africa show increased fire activity from 19-17 cal kyr BP, as do most sites from Indochina and Australia between 16-13 cal kyr BP. Many sites indicate increased fire activity during the Holocene, although fire activity was reduced in eastern North America and eastern Asia between 8 and $\sim 3$ cal kyr BP, Indonesia and Australia between 11 and 4 cal kyr BP, and in southern South America between 6-3 cal kyr BP.

Comparison of the charcoal-based reconstructions with other paleoclimatic records suggests explanations for the reconstructed changes in fire regimes (see Power et al., in press), but diagnosing the underlying causes of these changes re- quires modeling of the coupled vegetation-fuel-fire system. The GPWG is currently using LPJ-SPITFIRE-a coupled dynamic global vegetation-fire model (Thonicke et al., subm) - to examine the impact of midHolocene (ca. 6 cal kyr BP) and the LGM (ca. 21 cal kyr BP) climates on vegetation and fire. These simulations, driven by climate output from coupled ocean-atmosphere general circulation models from the Palaeoclimate Modelling Intercomparison Project (PMIP2), show surprisingly good matches to the reconstructed fire regimes.

At a workshop in October, sponsored by the UKNERC-sponsored QUEST (Quantifying and Understanding the Earth System) program, iLEAPS and PAGES, members of the GPWG mapped out their future activities. These include: (1) continued expansion of the charcoal database, (2) analysis of the causes and consequences of changes in fire regimes over the last interglacialglacial-interglacial cycle, (3) development of new interpretive tools, and (4) creation of benchmark model-evaluation data sets for the Fire Model Intercomparison Project (FIREMIP). The GPWG currently has over 90 members worldwide, and welcomes participation by all scientists interested in understanding the role of paleofire in the Earth System.

\section{References}

Power, M.J., et al., in press: Changes in fire regimes since the Last Glacial Maximum: an assessment based on a global synthesis and analysis of charcoal data, Climate Dynamics, [DOI 10.1007/ s00382-007-0334-x].

Thonicke, K., Spessa, A., Prentice, I.C., Harrison, S.P. and Carmona-Moreno, C., submitted: The influence of vegetation, fire spread and fire behaviour on global biomass burning and trace gas emissions, Global Change Biology.

\title{
Mangrove paleoecology and environmental change
}

\section{Cairns, Australia, 29 July 2007}

\author{
Matthew Wooller \\ University of Alaska Fairbanks, USA; ffmjw@uaf.edu
}

Cairns, Australia was a most appropriate venue for a research session dedicated to mangrove paleoecology. Held at the INQUA 2007 meeting, the session was supported by PAGES and the US NSF. Mangrove ecosystems are productive and important economic resources for people living in tropical coastal areas. They are also highly susceptible to sea level changes and can form protective barriers against wind, flooding, erosion and tsunami damage. Information on past mangroves is imperative in understanding the effects of present and possible future ecological changes. The mangrove paleoecology session brought together researchers studying how mangroves respond to environmental changes. A further objective of the session was to promote the representation of researchers from developing countries, where mangroves are important ecosystems. Towards this goal, PAGES funds supported two researchers (Marcelo Cohen, Brazil and Sauren Das, India) to attend the meeting.

The session, which consisted of four sub-sessions over two days, was co-convened by Matthew Wooller, Hermann Behling, Simon Haberle and Marcelo Cohen and consisted of oral and poster presentations. With study sites included from Brazil, Belize, India, New Zealand, Indonesia and Australia, the session succeeded in its objective to provide a pan-tropical

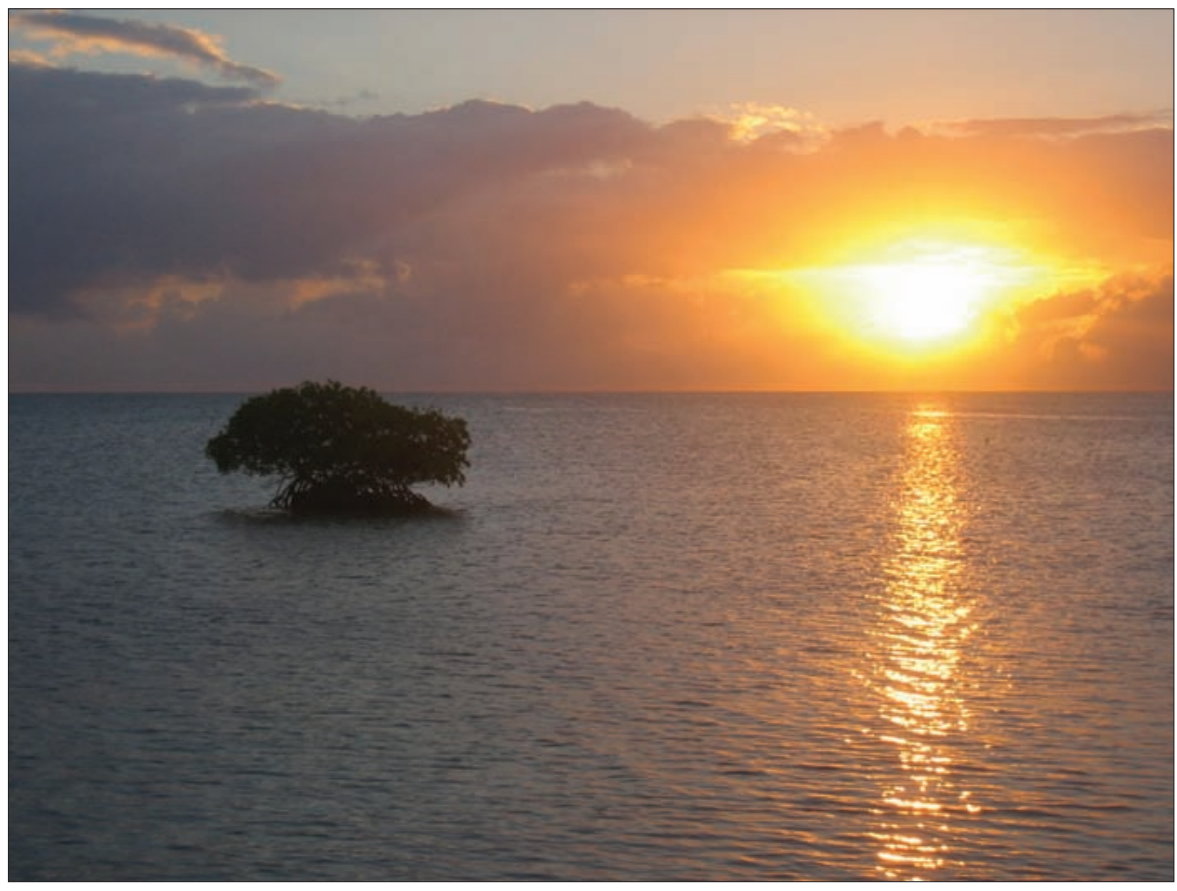

Figure 1: A Rhizophora mangle (red mangrove) tree off the coast of Belize, Central America. A number of presentations in the session illustrated the abilities of mangroves to track and respond to sea level changes. For instance, stands dominated by R. mangle have been able to maintain mangrove habitats off the coast of Belize for at least the last $\sim 8,000$ years of sea level changes. (photo: M. Wooller).

perspective of mangrove paleoecology. The session also succeeded in providing examples of the diverse array of paleoecological techniques needed to understand past mangrove ecological changes.

Patrick Moss began the session with a record from ODP 820 marine core (northeastern Australia) of mangrove paleoecol- ogy covering the last million years. James Westgate and Carole Gee followed with faunal and floral ecological reconstructions from the middle Eocene mangroves in Texas. Although these two talks fell outside the Quaternary theme they provided valuable perspectives of mangrove antiquity and the challenges associated with 
studying these ancient ecosystems. As a temporal contrast, John Cann and Catherine Lovelock presented recent historical data from the northern shores of South Australia and a rapidly-prograding waveexposed coast in New Zealand. These presentations illustrated the influence of sedimentation in mangrove ecosystem dynamics.

The remaining talks in the session presentd Holocene reconstructions of mangrove environments. Marcelo Cohen and Hermann Behling presented palyological studies of numerous cores from mangrove sites in Brazil during the Holocene, reconstructing vegetation dynamics during relative sea level changes. Natalie Monacci presented pollen-based reconstructions of Holocene mangrove dynamics from Belize. She also showed additional proxies of past environments, including stable isotope analyses ( $\mathrm{C}, \mathrm{N}$ and O) of mangrove leaves preserved in peat cores. Marilyn Fogel followed with details of biomarker analyses of the same cores. Compounds specific to different mangroves and microbial communities were used to complement pollen data to reconstruct past ecosystem composition. Sarah Woodroffe subsequently presented foraminiferal assemblage data derived from mangrove sediments as a proxy of past sea level during the Holocene in tropical north Queensland, Australia. Arghya Hait took a palynological approach to the reconstruction of mangroves of the Chamta and Sudhyanyakhali Islands of the Sundarban Biosphere Reserve, India. Simon Engelhart also focused on a palynological approach but concentrated on a modern calibration set as a method of reconstructing Holocene sea levels and paleoenvironments of southeast Sulawesi, Indonesia. Sauren Das, finished the session by providing a paleoecological reconstruction of the Lower Bengal Basin, Calcutta, India during the Holocene.

The session illustrated the wide range of paleoecological approaches, both traditional and innovative, for reconstructing past mangrove environments. A common finding based on paleoecological inferences from a number of the studies and locations was evidence for significant variability in relative sea level during the Holocene.

\title{
International workshop on environmental changes and sustainable development in arid and semi-arid regions
}

\author{
Alashan Left Banner, Inner Mongolia, China, 10-14 September 2007
}

\author{
XIAOPING YANG \\ Institute of Geology and Geophysics, Chinese Academy of Sciences, Beijing; xpyang@mail.igcas.ac.cn
}

The prevailing point of view in many early textbooks was that sand seas experienced an arid climatic optimum in the Holocene, whereas glacial maxima were pluvially active. More recently, an extension of the sand seas during the Last Glacial Maximum (LGM), and a retreat during the Holocene climatic optimum, has been reported. Yet, with considerable improvement in dating techniques (particularly luminescence dating), new data from various deserts of the world suggest a much more complicated picture of desert landscape evolution. The International Workshop on Environmental Changes and Sustainable Development in Arid and Semi-arid Regions was recently held in Inner Mongolia, China. This workshop aimed to compare regional-scale reconstructions of late Quaternary changes in the deserts of various climate zones (monsoon regions, subtropics and westerlies), and to discuss case studies and theories relating to land degradation and sustainable development, geomorphological processes, and interactions between human and natural factors. 83 delegates from 17 countries attended (Fig. 1).

In his opening speech, Jiaqi Liu, Chairman of the Organizing Committee, emphasized the significance of dryland studies in understanding global changes, and for re- gional developments in China and the rest of the world. Five keynote presentations followed, giving an overview of recent research progress on natural and anthropogenic impacts on arid environments, in addition to land management issues. Andrew Goudie presented sources and trends of desert dust, Ying Wang talked about the origins of the sands in Chinese deserts, Bojie Fu analyzed the problems of land degradation and rehabilitation measurements in China, Arthur Conacher highlighted the future of research in managing

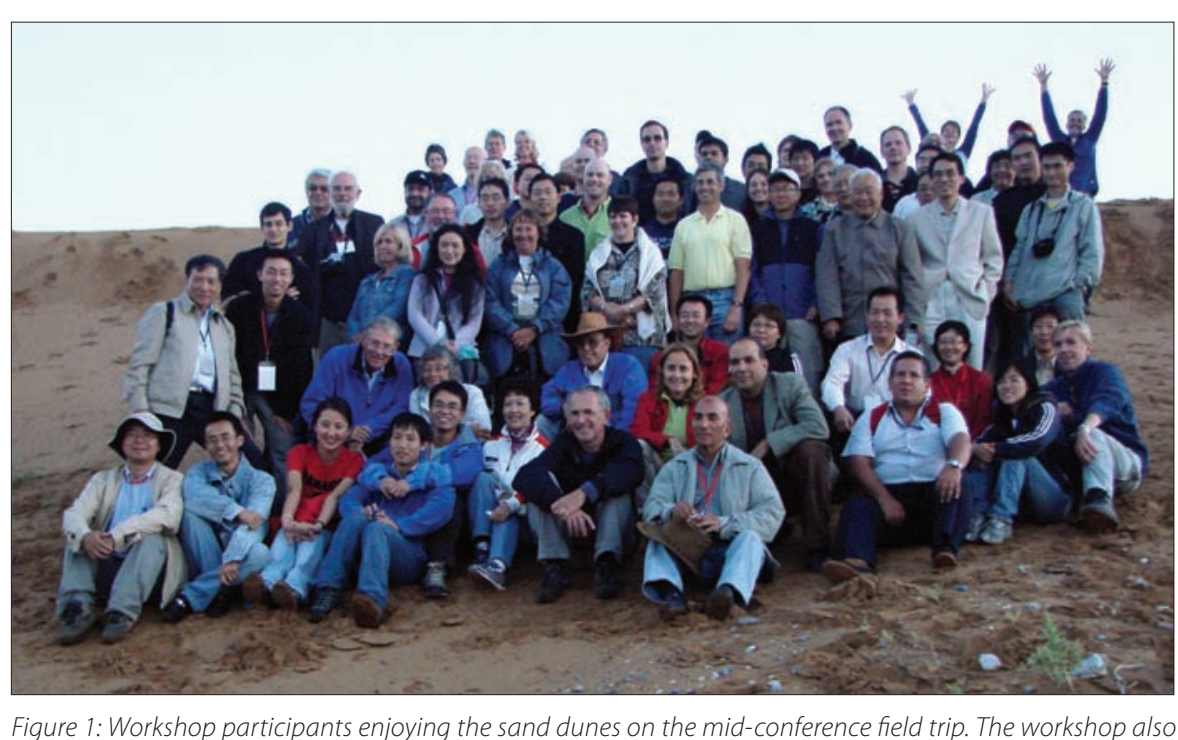

Figure 1: Workshop participants enjoying the sand dunes on the mid-conference field trip. The workshop also included two optional field trips to active and stable dunes in Inner Mongolia. land degradation, and Jianguo (Jingle) Wu demonstrated a scientific framework for sustainable development in arid and semiarid regions, with particular reference to the Inner Mongolia grassland. The program that followed included numerous oral presentations and posters.

What became increasingly evident over the course of the workshop was the degree of difference between paleoclimate reconstructions from different regions. New dating indicates that dune sand accumulation in South Australia continued 